\title{
Estimation of geotechnical parameters on the basis of geophysical methods and geostatistics
}

\author{
Aleksander Brom $^{1,2 *}$, Adrianna Natonik ${ }^{1}$ \\ ${ }^{1}$ Faculty of Earth Sciences, University of Silesia in Katowice, Będzinska 60, 41-200 Sosnowiec, Poland \\ ${ }^{2}$ Science Student Society of Geophysics PREM, University of Silesia in Katowice, Będzińska 60, 41-200 \\ Sosnowiec, Poland \\ *corresponding author: aleksander.brom@gmail.com
}

Received: $21^{\text {st }}$ June, 2017

Accepted: $19^{\text {th }}$ July, 2017

\begin{abstract}
The paper presents possible implementation of ordinary cokriging and geophysical investigation on humidity data acquired in geotechnical studies. The Author describes concept of geostatistics, terminology of geostatistical modelling, spatial correlation functions, principles of solving cokriging systems, advantages of (co-)kriging in comparison with other interpolation methods, obstacles in this type of attempt. Cross validation and discussion of results was performed with an indication of prospect of applying similar procedures in various researches..
\end{abstract}

Key words: geostatistics, semivariogram, kriging, cokriging

\section{Introduction}

Spatial correlation is a common phenomenon in geology, connected to Tobler's First Law of Geography. The scientist stated that „everything is related to everything else, but near things are more related than distant things (Tobler 1970). Geostatistics is a branch of applied statistics that deals with analysis of random events taking into consideration spatial information. Although the geostatistics stems from geology, nowadays it also serves in environmental, social, economical and medical issues. The geostatistics is applied predominantly to estimate the degree of environment contamination and the parameters of deposit during prospection as well as production.

This branch has developed unique methods allowing preparation of spatiotemporal analyses and forecasts of examined phenomena while using different datasets. We will focus on two of them: kriging and cokriging. Kriging is a Best Linear Unbiased Estimator (BLUE) and it is used in interpolation of datasets with only one variable. In order to improve estimations, save time and reduce cost cokriging procedures and multivariable datasets are implemented. Cokriging allows integration of primary variable with at least one secondary variable to improve results. It also facilities the process of combining the historical and present data, even if they might have been measured with different accuracies.

The objective of this paper is to describe the possible elaboration of geotechnical data (soil humidity obtained from drilling) with geophysical survey and geostatistics. Undoubtful correlation between soil water content and electrical conductivity justifies application of this geostatistical approach (Pozdnyakova 1999; Kondracka 2013). However, we should remember that electrical properties of soils depend not only on water content, but also mineral composition, porosity, firmness and chemical composition of pore fluids (Hersir and Arnason 2010; Olhoeft 1981).. 


\section{Methodology}

The main obstacle in geostatistical analysis is to quantify spatial correlations. Two different realizations of the same variable in space can be linked with a vector (Fig. 1).

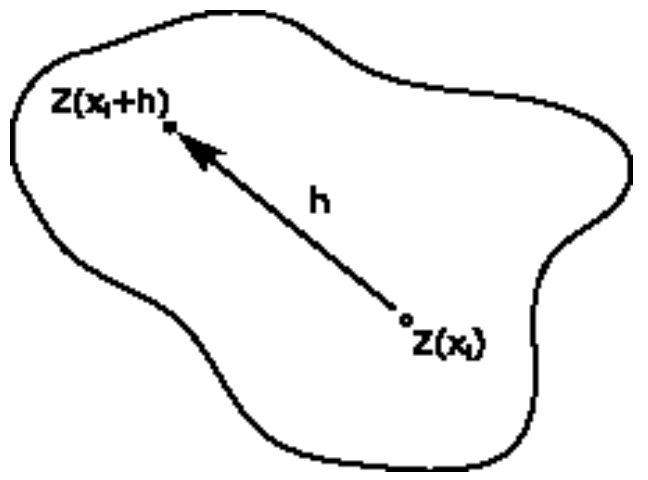

Fig.1. Lag vector connecting two points with known realizations of regionalised function (after Wackernagel 2003).

The term „spatial variability is often replaced with „spatial continuity" to emphasize the impact of samples on each other but they can be used interchangeably. Realization's discrepancy between $\mathrm{x}$ and $\mathrm{x}+\mathrm{h}$ is defined as (Remy et al. 2009):

$\gamma(h)=\frac{\left[Z\left(x_{1}\right)-Z\left(x_{1}+h\right)\right]^{2}}{2}$

a)

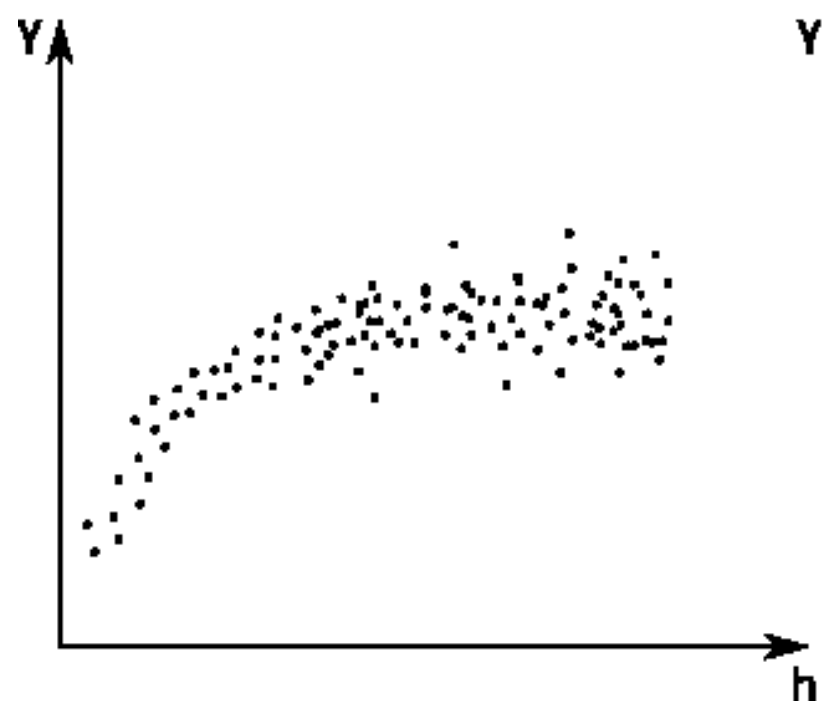

Measured data represent observation sequence of regionalized function on selected area. It permits creation of points' pairs set with different collection length $h$. Afterwards we plot discrepancy values as a function of lag vector (length $\mathrm{h}$ ) receiving a plot called a variogram (or semivariogram) cloud which is a base for creating theoretical semivariogram. The example of a variogram cloud is shown on Fig. 2.

While calculating ordinary kriging only semivariograms are used when cokriging is using also cross-semivariograms. They are identical in construction but they join two different variables.

$$
\begin{aligned}
& \gamma_{U Y}(h)=\frac{1}{2 N(h)} \sum_{(i, j) h_{i j}=h}\left[U\left(x_{i}\right)-U\left(x_{i}+\right.\right. \\
& h)] *\left[Y\left(x_{i}\right)-Y\left(x_{i}+h\right)\right]
\end{aligned}
$$

For stationary cases (when average and variance in each point in time and space are identical) it is possible to use covariance and semivariance interchangeably.

Figure 3 shows typical shape of semivariogram. Modelling of such semivariogram requires following parameters:

- Range (of influence) $a$

- Sill $c$

- Nugget effect $c_{0}$

b)

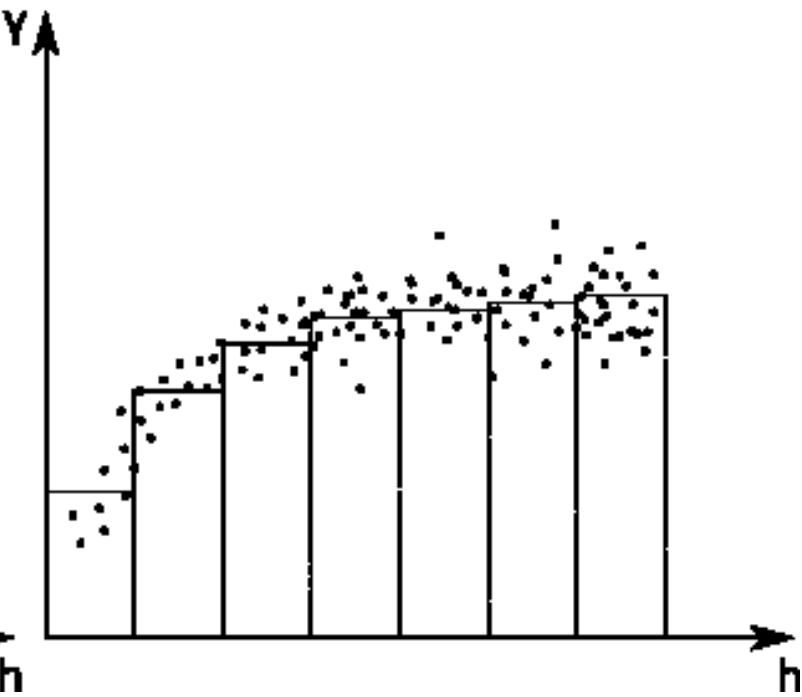

Fig.2. Variogram cloud (a) with applied class separation (considered equidistant) (b) (after Wackernagel 2003). 


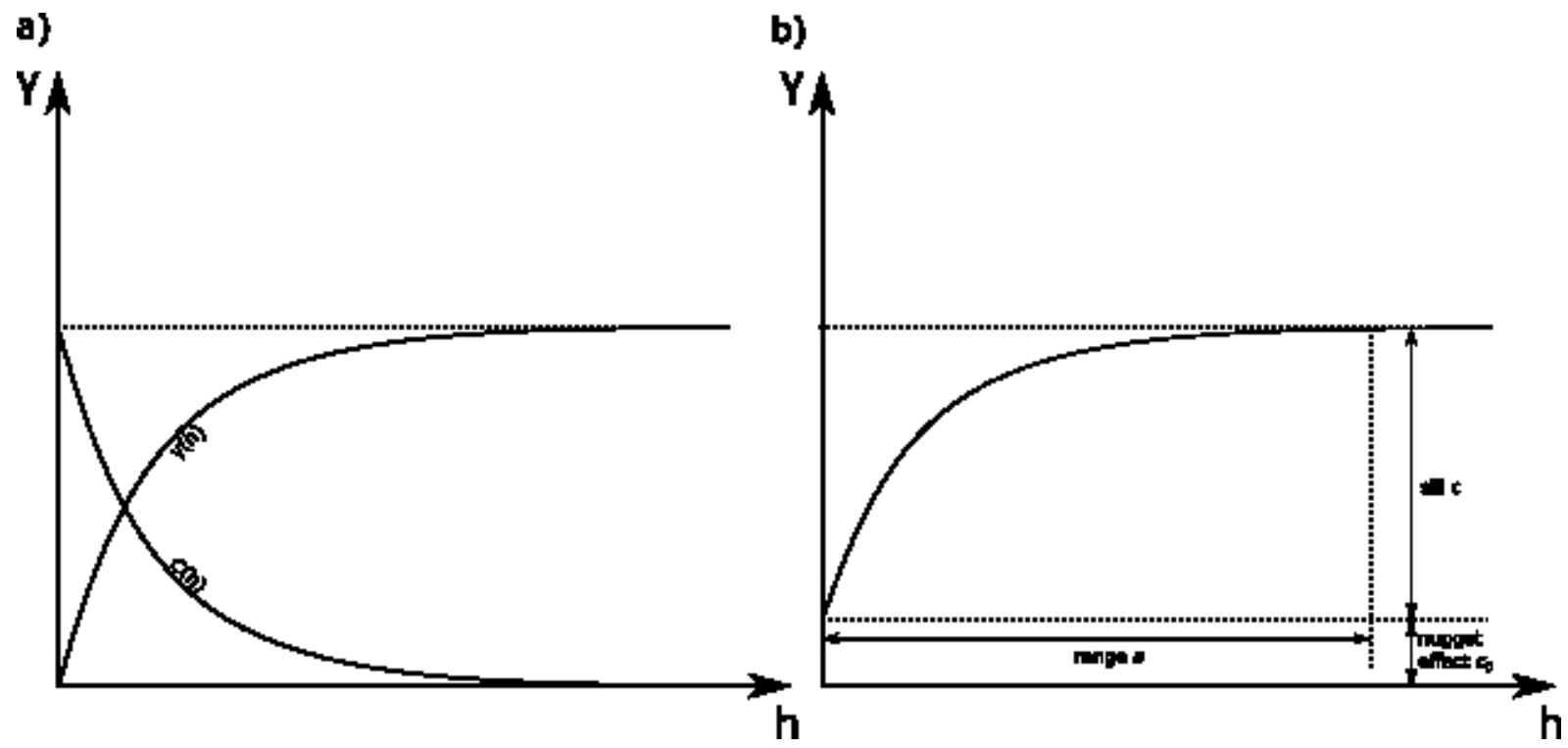

Fig.3. Relationship between covariance function $\mathrm{C}(\mathrm{h})$ and semivariance $\gamma(\mathrm{h})$ (a) Exemplary theoretical semivariogram with distinctive parameters (b) (after Isaaks and Srivastava 1989).

Range of influence $a$ defines the range of existing spatial correlations - in other words, it is the maximal distance between two points we can observe the correlations between them. In Fig. 3 range is the distance on $\mathrm{x}$-axis when the semivariogram reaches saturation. When there is no correlation between values $\mathrm{Z}\left(\mathrm{x}_{\mathrm{i}}\right)$ and $\mathrm{Z}(\mathrm{xi}+\mathrm{h})$, semivariance is equal to variance of analysed population (Zawadzki 2011):

$$
\begin{aligned}
& \gamma(h)=\frac{1}{2} \operatorname{Var}\left[Z\left(x_{i}+h\right)-Z\left(x_{i}\right)\right]= \\
& \frac{1}{2}\left[\operatorname{Var}\left(Z\left(x_{i}+h\right)+\operatorname{Var}\left(Z\left(x_{i}\right)\right)\right)\right]=\sigma^{2}
\end{aligned}
$$

Not all semivariograms reaches saturation and in such cases (non-stationary) it is impossible to use covariance function for examining correlation between random variables by virtue of (Isaaks and Srivastava 1989):

$C(h)=C(0)-\gamma(h)$

because $\mathrm{C}(0)$ is infinite.

Sill $c$ is another parameter representing the value of threshold variance. It is the value of semivariogram's $\gamma(a)$ saturation. Sill is equal to total variance of surveys. For unlimited semivariograms the sill does not exist.

The last parameter is the value of semivariance for vector $\mathrm{h}=0$ - Y-intercept of a function $\gamma$. It is called the nugget effect $c_{0}$. In theory semivariogram in coordinate system origin should equals 0 . Positive values for $\mathrm{h}=0$ might be caused by measurement error or/and by existence of nested structures in the distance smaller than sampling spacing. The term 'nugget effect' derived from gold grains haphazardly dispersed in ground space (Zawadzki 2011).

The theoretical semivariogram from empirical data can be described in many ways. For example, it might consist of few semivariograms connected to create a nested model. We can distinguish the following types of theoretical semivariograms (Zawadzki 2011; Remy et al. 2009):

- Pure nugget effect

$\gamma(h)=\left\{\begin{array}{c}0 \text { for } h=0 \\ c_{0} \text { for } h \neq 0\end{array}\right.$

- Spherical model

$$
\begin{aligned}
& \gamma(h)= \\
& \left\{\begin{array}{l}
c_{0}+\left(c-c_{0}\right)\left(\frac{1,5 h}{a}-\frac{0,5 h^{2}}{a^{2}}\right) \text { for } h \leq a \\
c \quad \text { for } h>a
\end{array}\right.
\end{aligned}
$$


- Exponential model

$\gamma(h)=$

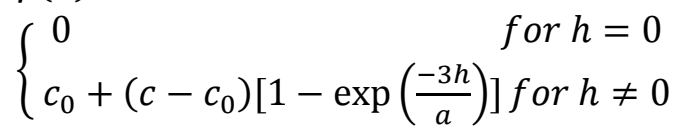

\section{Cokriging}

When we acquired two data sets representing different regionalized variables it is recommended to ply cokriging method. The most common situation is when the primary variable was collected sparsely (due to high cost, time consumption or environmental protection) whereas secondary (auxiliary) variable was sampled densely or even excessively. These variables do not need to be strongly associated, only requirement is any correlation. This geostatistical estimation technique allows to (Webster and Oliver 2007):

- Reduce costs,

- Decrease the variation of estimation errors,

- Improve estimation by even several dozen percents.

Cokriging assumes that the estimated value of regionalized variable is a linear combination of certain values. In this case these are both primary and secondary variables. It leads to (Zawadzki 2011):

$\widehat{U}\left(x_{0}\right)=\sum_{i=1}^{n} w_{i} U\left(x_{i}\right)+\sum_{j=1}^{m} t_{j} V\left(x_{j}\right)$

where:

$\widehat{U}\left(x_{0}\right)$ - estimated value of the primary variable, $U\left(x_{i}\right)$ - value of the primary variable in i-th point, $V\left(x_{j}\right)$ - value of the secondary variable in $\mathrm{j}$-th point, $w_{i}$ - cokriging weight for i-th value of the primary variable, $t_{j}$ - cokriging weight for $j$-th value of the secondary variable.

The above equation (8) has to hold following conditions:

1. Condition of estimator $\widehat{U}\left(x_{0}\right)$ unbiasedness is fulfilled by equating the sum of primary variable's weight to 1 and the sum of secondary variable's weight to 0

$$
\begin{aligned}
& \sum_{i=1}^{n} w_{i}=1 \\
& \sum_{j=1}^{m} t_{j}=0
\end{aligned}
$$

2. Condition of minimizing cokriging variance - fulfilled by Lagrange multipliers method.

To obtain cokriging weights it is required to solve the following set of equations (Xu et al. 2015):

$$
\begin{aligned}
& \left(\begin{array}{cccccccc}
C_{U U}\left(x_{1}, x_{1}\right) & \cdots & C_{U U}\left(x_{1}, x_{i}\right) & C_{V U}\left(x_{1}, x_{1}\right) & \cdots & C_{V U}\left(x_{1}, x_{i j}\right) & 1 & 0 \\
\vdots & \ddots & \vdots & \vdots & \ddots & \vdots & 1 & 0 \\
C_{U U}\left(x_{i}, x_{1}\right) & \cdots & C_{U U}\left(x_{i}, x_{i}\right) & C_{V U}\left(x_{i j}, x_{1}\right) & \cdots & C_{V U}\left(x_{i j}, x_{i j}\right) & 1 & 0 \\
C_{U V}\left(x_{1}, x_{1}\right) & \cdots & C_{U V}\left(x_{1}, x_{i j}\right) & C_{V V}\left(x_{1}, x_{1}\right) & \cdots & C_{V V}\left(x_{1}, x_{j}\right) & 0 & 1 \\
\vdots & \ddots & \vdots & \vdots & \ddots & \vdots & 0 & 1 \\
C_{U V}\left(x_{i j}, x_{1}\right) & \cdots & C_{U V}\left(x_{i j}, x_{i j}\right) & C_{V V}\left(x_{j}, x_{1}\right) & \cdots & C_{V V}\left(x_{j}, x_{j}\right) & 0 & 1 \\
1 & 1 & 1 & 0 & 0 & 0 & 0 & 0 \\
0 & 0 & 0 & 1 & 1 & 1 & 0 & 0
\end{array}\right)\left(\begin{array}{c}
w_{1} \\
\vdots \\
w_{i} \\
t_{1} \\
\vdots \\
t_{j} \\
\mu_{1} \\
\mu_{2}
\end{array}\right)= \\
& =\left(\begin{array}{c}
C_{U_{0} U}\left(x_{1}, x_{0}\right) \\
\vdots \\
C_{U_{0} U}\left(x_{n}, x_{0}\right) \\
C_{U_{0} V}\left(x_{1}, x_{0}\right) \\
\vdots \\
C_{U_{0} V}\left(x_{n}, x_{0}\right) \\
1 \\
0
\end{array}\right)
\end{aligned}
$$




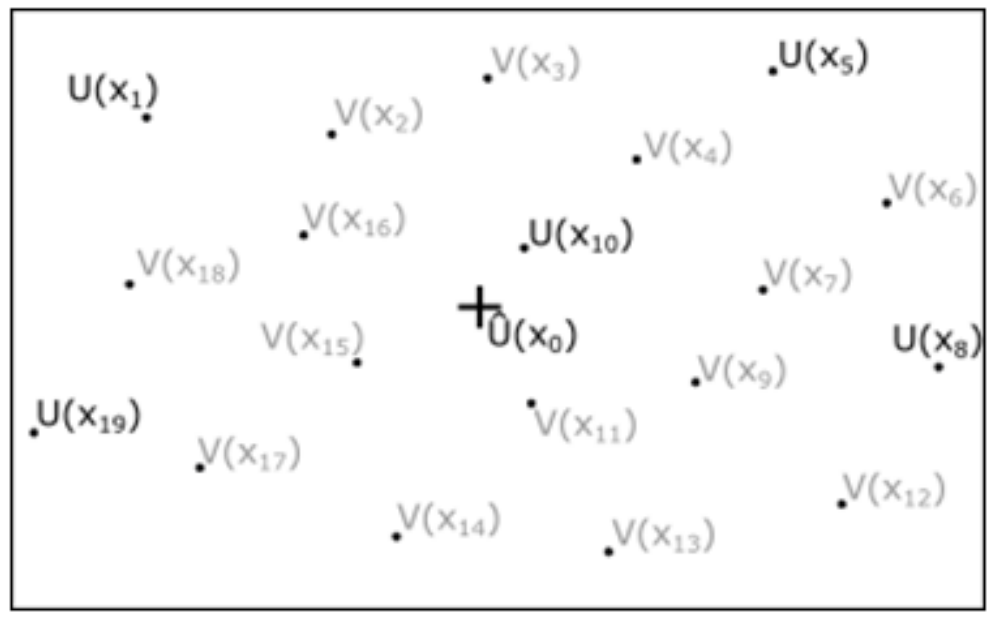

Fig.4. Application of cokriging in this situation might be beneficial for improving results. In black - measured primary variables, in grey - auxiliary variables.

\section{Localization}

The selected area is situated in Katowice at the intersection of Nadgórników and Dobrowolskiego Streets (see Fig.5).

The researched area is located on BytomKatowice Plateau. Bedrock consists of Carboniferous and Quaternary deposits. Carboniferous is represented by sandstones, mudstones and clayey shale with coal seams from saddle and Ruda beds. Top bed of those rocks is weathered and they changed into weathering clayey-stony waste with clasts and partings of rocks. Quaternary is represented by
Pleistocene cover formations. In the lower part of the section we can find sandy clay with sand lenses and the upper on is built with silty clay and silts (Biernat and Krysowska 1955-1960). Land surface had gone through many anthropogenic changes and is covered with mineral and rubble layer varying from $0.3 \mathrm{~m}$ to $8.6 \mathrm{~m}$ of thickness. This layer is a mixture of clay, sandy clay, silty clay and silts mixed with sands, gravels, rubble, slag and hummus. Since the area used to be the field of shallow exploitation, many pits can be found on the surface.

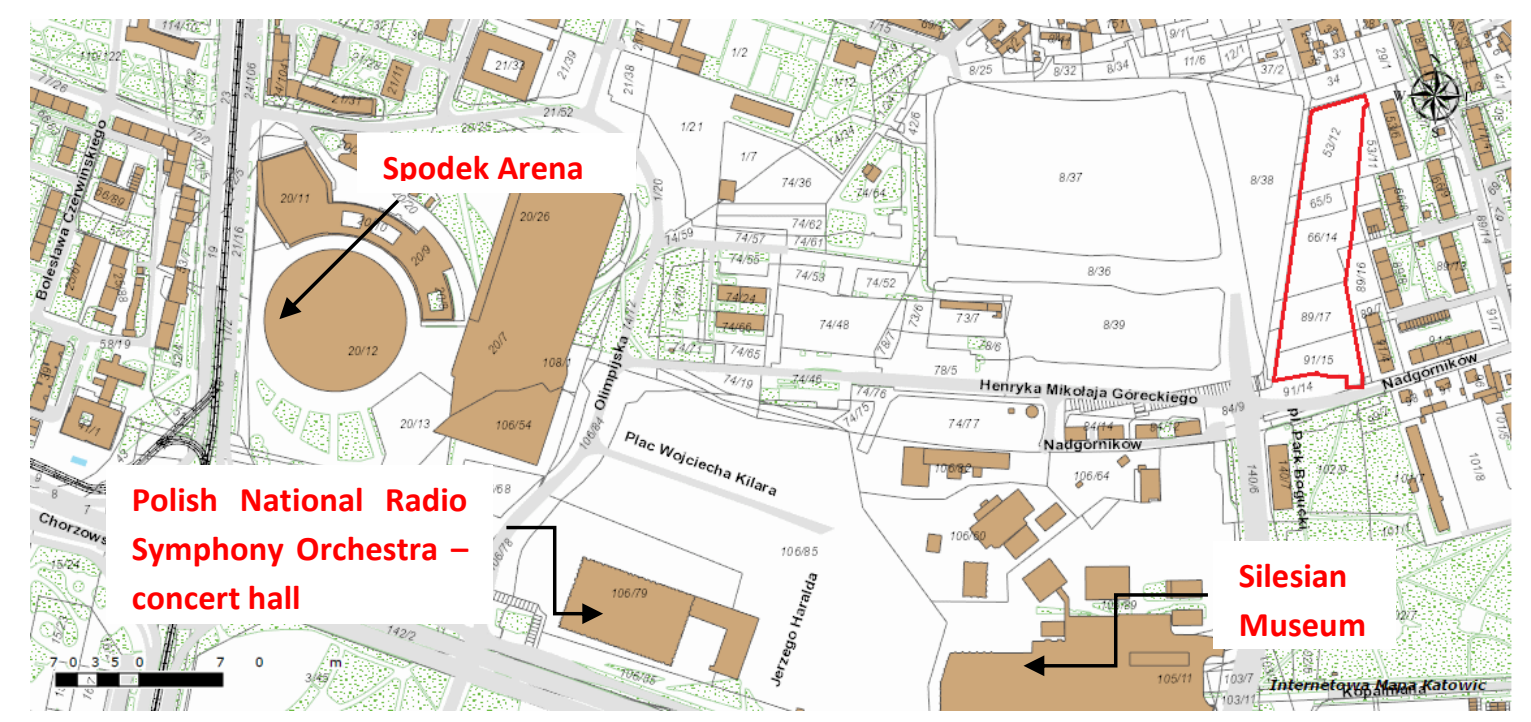

Fig.5.The selected are (red line) with nearby landmarks. (Source: Internetowe Mapy Systemu Informacji Przestrzennej Katowic http://mapserver.um.katowice.pl 


\section{Studies}

Firstly, 15 boreholes from $4.5 \mathrm{~m}$ to $14.0 \mathrm{~m}$ deep were drilled using Boart Longgear DB505 and Apafor 30 rigs without drilling fluid. 40 samples were taken from 12 of those boreholes. Humidity of the samples was connected to corresponding geotechnical layers. These data were collected and processed by one of the Silesian geological companies and were kindly offered for scientific purposes.

Secondly, three resistivity imaging (ERT) profiles were set out each $200 \mathrm{~m}$ long and with $5 \mathrm{~m}$ electrode spacing. The authors used Abem Terrameter SAS 4000 with WennerSchlumberger array. The inversion was made in RES2DINV (Loke 2000) and geostatistical calculations were made using free software SGEMS. To facilitate the calculations, we established the local coordinates system. The Yaxis coincides with western plot's boundary and $Z$-axis runs along height system from boreholes drilling. The system is shown on Fig. 6 .

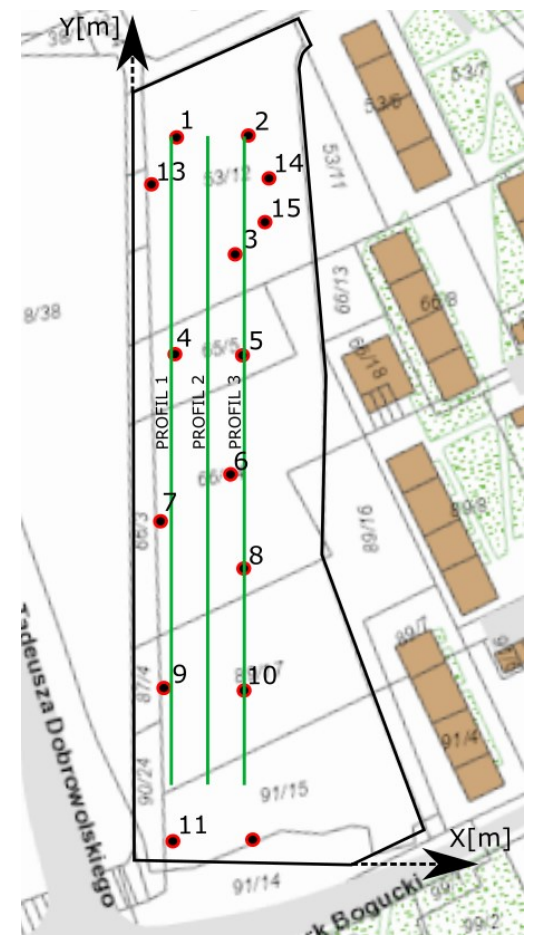

Fig.6. Established coordinates system with profiles and numbered boreholes. (Background: Internetowe Mapy Systemu Informacji Przestrzennej Katowic http://mapserver.um.katowice.pl)
Basing on geotechnical interpretation, we selected points within one layer to avoid differentiation of humidity-resistivity relations in disparate deposits. Set of 22 humidity points and 323 resistivity points was obtained. According to available geotechnical sources, the studied layer is weathering clayey-stony waste of clayey shale in shape of silty clay with rocky clasts and clayey-stony waste of sandstone, both with clayey cement.

All the data were subject to standardization. It means the data were changed so they mean is equal to 0 and variance is 1 . This process improved the calculations and allowed preparation of cross-plot shown on Fig. 7. However, the final results were restored to initial state to operate with actual values.

Analysed geotechnical profiles with charted resistivity profiles and discussed layer are shown on Fig. 8 and 9.

\section{Modelling of semivariograms}

Modelled theoretical semivariograms are shown on Fig. 10, 11 and 12. Received semivariogram can be described by following equations:

$$
\begin{aligned}
& \gamma_{H H}=0,1+0,60517 \operatorname{Sph}_{15,3}(h)+ \\
& 0,60517 \operatorname{Sph}_{9,0}(h)
\end{aligned}
$$

$\gamma_{R R}=0,05+0,50311 S p h_{12,5}(h)+$ $0,45 \operatorname{Sph}_{25,5}(h)$

$\gamma_{H R}=0,05+0,15 \operatorname{Sph}_{15,6}(h)+$ $0,15 \operatorname{Sph}_{9,0}(h)$

Made with the use of above relations, the calculations included full cokriging with search ellipsoid with equal axes of $50 \mathrm{~m}$ and $\max 20$ conditioning data for primary variable and $30 \mathrm{~m}$ and max 30 conditioning data for secondary one. Additionally, kriging variance in each point was calculated. Humidity results can be seen the mostly clear on humidity maps. Exemplary map is shown below on Fig. 13. 


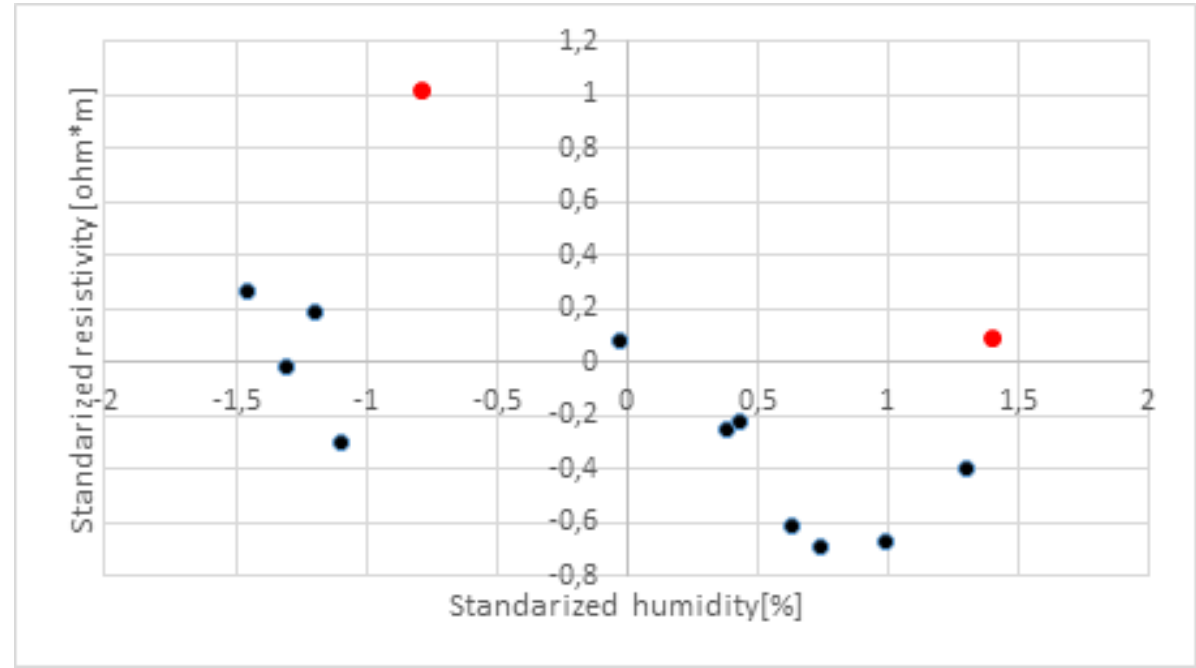

Fig.7. Cross-plot showing the relationships between two sets of data.

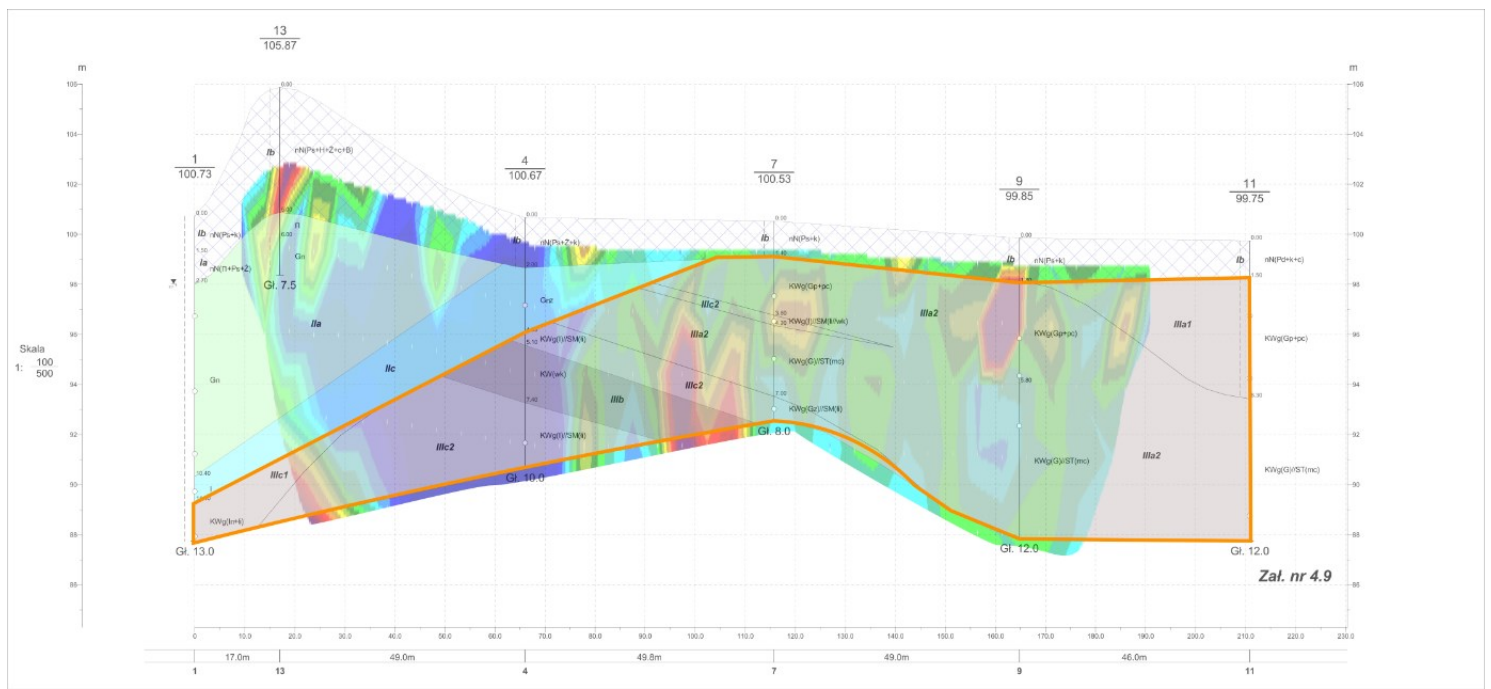

Fig.8. Geotechnical profile coincided with resistivity profile № 1

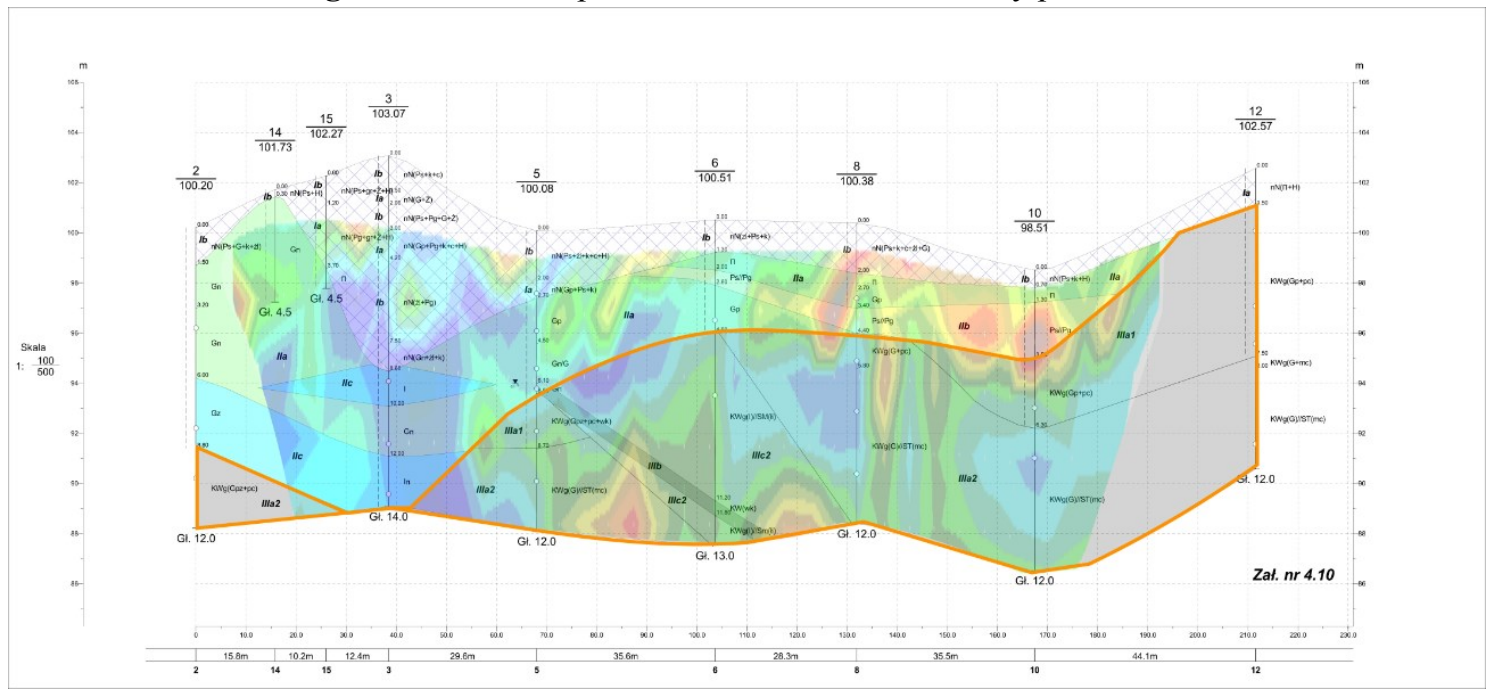

Fig.9. Geotechnical profile coincided with resistivity profile № 3 


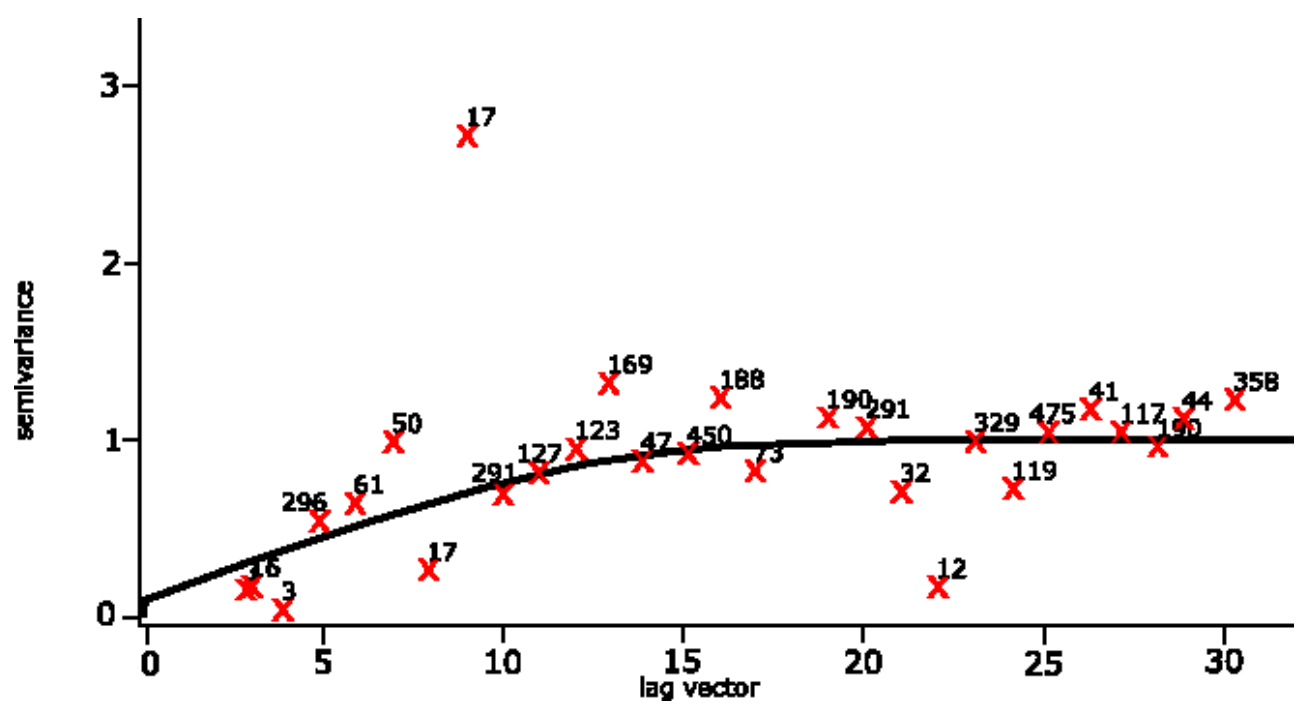

Fig.10. The theoretical semivariogram of standardized humidity. The numbers denotes obtained pair of points.

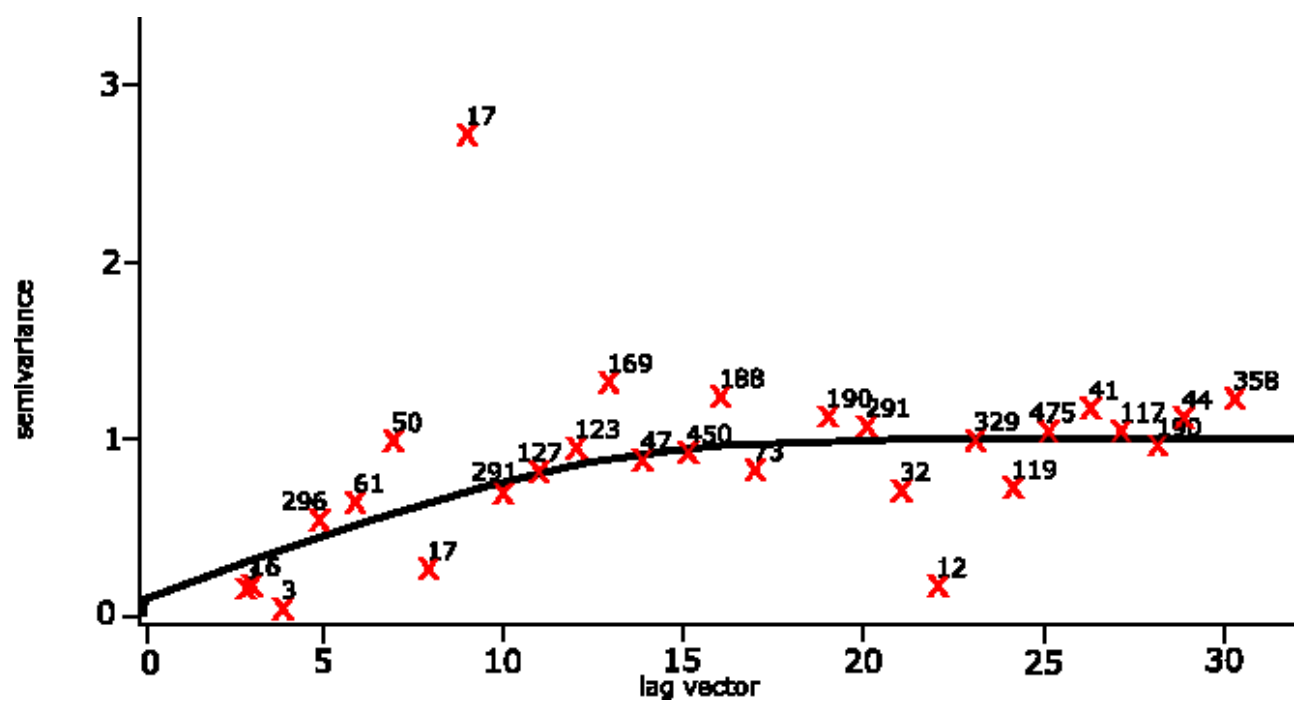

Fig.11. The theoretical semivariogram of standardized resistivity. The numbers denotes as above.

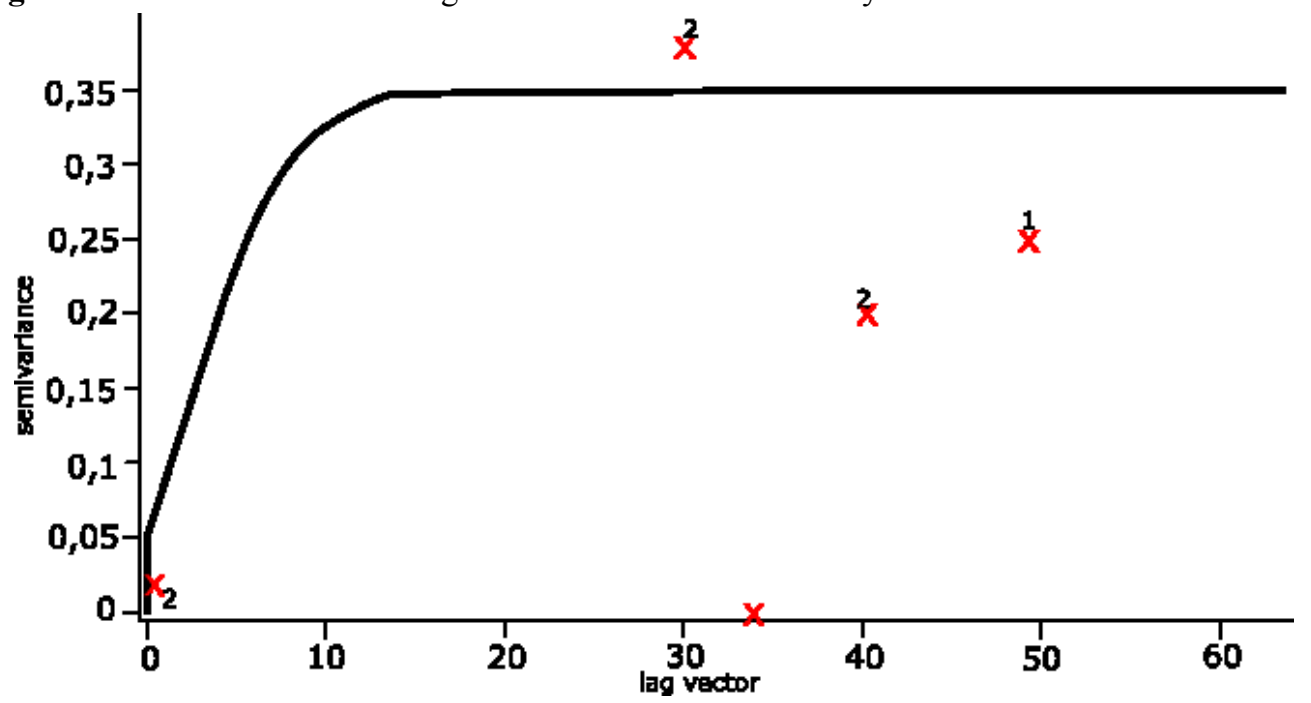

Fig.12. The theoretical cross-semivariogram of standardized humidity and standardized resistivity. The numbers denotes as above. 


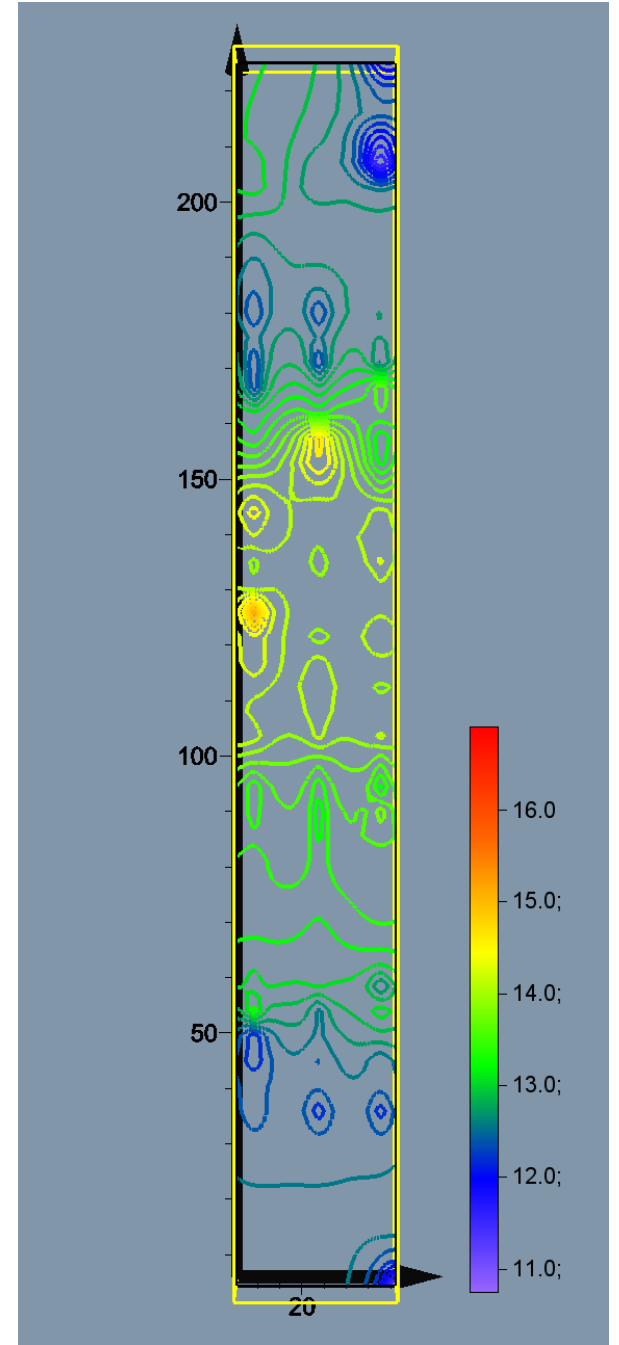

Fig.13. Exemplary results of humidity [\%] - crosssection from $92 \mathrm{~m}$ depth in local coordinates system.

\section{Cross-validation}

Cross-validation involves exclusion from kriging equation a single point with known primary variable and repeated calculation of those equations for this missing point. Using 13 points with known both variables, the validation was carried out 13 times. Results are shown in Table 1. Relative error was calculated as:

$\delta=\frac{h_{\text {act. }}-h_{\text {cal. }}}{h_{\text {act. }}}$,

where:

$\delta$ - relative error

$\mathrm{h}_{\text {act. }}$ - humidity measured in laboratory,

$\mathrm{h}_{\text {cal. }}$ - calculated humidity.
Tab.1. Summary of cross-validation

\begin{tabular}{|c|c|c|c|c|c|c|c|}
\hline \multicolumn{8}{|c|}{ Results of cross-validation } \\
\hline № & 1 & 2 & 3 & 4 & 5 & 6 & 7 \\
\hline $\begin{array}{l}\boldsymbol{h}_{\text {act. }} \\
{[\%]}\end{array}$ & 10,8 & 14,9 & 13,7 & 11,4 & 10,1 & 15,5 & 10,6 \\
\hline $\begin{array}{c}\boldsymbol{h}_{\text {cal. }} \\
{[\%]}\end{array}$ & 13,4 & 12,6 & 14,2 & 15,0 & 13,2 & 13,7 & 12,7 \\
\hline$\delta$ & 0,24 & 0,16 & $-0,04$ & $-0,31$ & $-0,30$ & 0,11 & 0,20 \\
\hline № & 8 & 9 & 10 & 11 & 12 & 13 & \\
\hline $\begin{array}{l}\boldsymbol{h}_{\text {act. }} \\
{[\%]}\end{array}$ & 13,8 & 15,7 & 12,9 & 14,2 & 10,4 & 14,4 & \\
\hline $\begin{array}{l}\boldsymbol{h}_{\text {cal. }} \\
{[\%]}\end{array}$ & 12,6 & 13,9 & 12,3 & 12,8 & 15,4 & 11,5 & 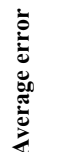 \\
\hline$\delta$ & 0,08 & 0,11 & 0,04 & 0,10 & $-0,48$ & 0,20 & 0,18 \\
\hline
\end{tabular}

\section{Discussion}

The research proved that it is possible to remodel humidity basing on conductivity of geological deposits but it should be limited to only one lithological type. The error of calculations is about $18 \%$ as it arises from the cross-validation.

Underground data, collected on the surface by ERT technique combined with resistivity inversion, allow avoiding limitations of other methods of humidity measuring, such as gravimetry, tensiometry, electrical resistivity, permittivity or neutron scattering which need physical contact with measured sample.

\section{Conclusions}

1. It is possible to remodel humidity on the basis of geostatistical approach and electrical resistivity tomography.

2. It is attainable to select zones with elevated or lessened humidity of soil which might be profitable information for constructors.

3. Due to limited borehole data available, modelling of humidity semivariance and cross-semivariance was straitened. If the character of sampling had been adjusted to 
geostatistical analysis (fixed sampling interval), the results would have improved.

\section{References}

Biernat S., Krysowska M. (1955-1960) The Detailed Geological Map of Poland (Szczegółowa mapa geologiczna Polski), scale 1:50 000, sheet: M-34-63-A (№ 943) Katowice, Polish Geological Institute, Warsaw, (In Polish).

Hersir G., Árnason K. (2010) Resistivity of Rocks, conference materials: Short Course on Exploration for Geothermal Resources

Isaaks E., Srivastava R. (1989) An Introduction to Applied Geostatistics, Oxford University Press, New York.

Kondracka M. (2013) The Impact of MiningMetallurgical Landfills of $\mathrm{Zn}-\mathrm{Pb}$ Ore on Soil Contamination in the Light of Geophysical Surveys (Wpływ składowisk odpadów górniczo-hutniczych rud $\mathrm{Zn}-\mathrm{Pb}$ na zanieczyszczenie gruntów w świetle badań geofizycznych), dissertation, University of Silesia (In Polish).

Loke, M.H. (2000) Topographic Modelling in Resistivity Imaging Inversion. 62nd EAGE Conference \& Technical Exhibition Extended Abstracts, D-2.
Olhoeft, G. R. (1981) Electrical properties of rocks. Physical properties of rocks and minerals, 2, 257-297.

Pozdnyakova L. (1999) Electrical Properties of Soils, dissertation, University of Wyoming.

Remy N., Boucher A., Wu J. (2009) Applied Geostatistics with SGeMS A User's Guide Cambridge University Press, New York

Tobler, W. (1970) A computer movie simulating urban growth in the Detroit region. Economic Geography, 46, 234-240.

Wackernagel H. (2003) Multivariate Geostatistics an Introduction with Applications, Springer Ver., Berlin, 387

Webster R., Oliver M. (2007) Geostatistics for Environmental Scientists, John Wiley \& Sons Ltd, West Sussex.

Xu H., Sun J., Russell B., Innanen K. (2015) Porosity prediction using cokriging with multiple secondary datasets, CREWES Research Report - Volume 27.

Zawadzki J. (2011) Geostatistics methods for environmental and technical courses (Metody geostatystyczne dla kierunków przyrodniczych i technicznych). Publishing House of Warsaw University of Technology, Warsaw. (In Polish) 